\title{
Eu aprendi e ensinei também ao mesmo tempo: professores leigos na história da escola rural
}

\author{
I also learned and taught at the same time: lay teachers in the \\ history of the rural school
}

Sandra Cristina Fagundes de LIMA'

\begin{abstract}
Resumo
A discussão incidiu sobre alguns problemas que perpassam o espaço rural e suas escolas, e sobre as táticas empreendidas por seus professores para se apropriarem do espaço e transformarem-no em lugar pleno de significaçóes. Os resultados obtidos com a pesquisa empírica e bibliográfica demonstram que, no âmbito da investigaçáo científica, a superação de uma análise naturalizada do rural e de suas escolas, bem como a edificação de outros caminhos para a escola em meio rural, demandam apreender historicamente os problemas daquele meio, e tomar a cultura empírica de seus professores como dimensão formativa e elemento da cultura escolar.
\end{abstract}

Palavras-chave: História da Escola Rural. Escolarizaçáo Rural. Professores Leigos. Cultura Empírica.
Abstract

The discussion has focused both on problems that have permeated the rural area with its schools, and teachers' strategies to transform space into a place full of meanings. The results show that in the scientific research context, overcoming a naturalized analysis of the rural place and its schools as well as building other paths to the school in rural areas, requires both a historical apprehension of the environmental problems, and taking the teacher empirical culture as a formative dimension and element of the school culture.

Keywords: History of the Rural School. Rural Schooling. Lay Teachers. Empirical Culture.

1 Doutora em História pela UNICAMP, Coordenadora do Grupo de Pesquisas em História do Ensino Rural (GPHER), Professora Associada da Universidade Federal de Uberlândia, Endereço: Av. João Naves de Ávila, 2121, Campus Santa Mônica, Sala 1G156, Uberlândia/MG- CEP: 38.408-100. Tel.: (34).3239.4197, FAX (34)3239.4391. Email: <sandralima@ufu.br>.

R. Educ. Públ.
Cuiabá

v. 27

n. $65 / 1$

p. $405-423$ maio/ago. 2018 


\section{A cidade, o rural e o silêncio: uma política?}

No último 31 de agosto ${ }^{2}$, Uberlândia, cidade situada no interior de Minas Gerais na sub-regiáo do Triângulo Mineiro, festejou os seus 129 anos de emancipação política. Como sempre ocorre às vésperas dessa data, abundaram homenagens à aniversariante, foram programados os eventos característicos dessa natureza de comemoração, tais como: desfiles, discursos, shows, apresentaçóes musicais, reportagens, publicação de revistas comemorativas, etc. No mundo dominado pela tecnologia, tudo isso foi divulgado frenética e ininterruptamente nas redes sociais e circulou pelo celular por meio do aplicativo Wathsapp. Haja memória no aparelho para tanta fotografia e vídeo que se compartilhou na ocasião!

Contudo, não foram as láureas em si, a pletórica divulgação e tampouco a diversidade dos espetáculos o que chamou a atenção, mas, sim, os seus conteúdos, que mesmo abordando aspectos ligeiramente diferentes guardavam um traço em comum: a centralidade do urbano, da cidade, de suas edificaçóes, ou seja, de seus "[...] lugares de memória" (NORA, 1993, p. 7) em detrimento do rural. Não se encontravam nesses tributos referências ao rural, ao seu papel na constituição do município, aos seus indicadores econômicos, suas escolas e nem aos sujeitos que ali habitam ou habitaram - esses também ausentes das imagens da cidade, com exceção daqueles de "[...] nome próprio" (RANCIÉRE, 1994, p. 9). O dever de memória subjacente a tal exaltação não incorporou a história do mundo rural à trajetória exitosa de Uberlândia, ao contrário, relegou aquela ao silêncio. ${ }^{3}$

Essa estratégia de silenciamento do rural não é inédita em se tratando da história do município. Conforme consta da ata da primeira reunião da Associação Comercial, Industrial e Agropecuária de Uberlândia (Aciapu), ocorrida em 1933, um dos associados propôs, sem resultado naquele momento, que fosse retirado da instituição o nome agropecuária com a justificativa de que só o comércio interessava ${ }^{4}$ (ASSOCIAÇÃO, 1933). Assim, conforme apropriadamente analisam Silveira e Ribeiro (2016), por remeter ao espaço rural a expressão agropecuária

2 Este texto, apresentado na mesa redonda Educação no meio rural, politicas, espaço e temporalidades, no $25^{\circ}$ SEMIEDU - UFMT (CUIABÁ, 2017), foi concluído em setembro de 2017, portanto, todas as alusões ao presente imediato têm como limite tal período.

3 O rural que a comemoração evidenciou foi aquele do agronegócio e do espetáculo. Durante dez dias a exposição agropecuária reuniu no parque do CAMARU centenas de pessoas que iam realizar negócios, como, por exemplo, a compra e venda de gado, e buscar diversão nos concorridos shows animados por bandas e duplas de música sertaneja.

4 A supressão da palavra agropecuária só teria ocorrido em 1969, quando a entidade passou a se denominar Associação Comercial e Industrial de Uberlândia (ACIUB) (SILVEIRA; RIBEIRO, 2016). 
poderia conspurcar a utopia urbano/desenvolvimentista que se gestava nos discursos das elites. Contudo, conforme indica Pollak (1989), silêncio não é sinônimo de esquecimento, ao contrário, denota uma dada gestão da memória, muito afeita às comemoraçóes, segundo a qual são impostos deveres de memória em detrimento do direito à memória, para cuja efetivação exige-se um trabalho de higienizar o passado, de edificá-lo a partir dos acontecimentos recortados como memoráveis, dentre os quais não há espaço para uma realidade de carências como aquela vivida pelos habitantes do meio rural, pois "Comemorar significa, então, [...] a sacralização dos grandes valores e ideais de uma comunidade constituindose no objetivo principal" (SILVA, 2002, p. 432).

A história da escola primária em meio rural ${ }^{5}$ também não encontrou lugar nessa comemoraçáo. Acrescento que sobre tal história recaem outros silêncios, quais sejam: o das políticas públicas e dos políticos, que não dotaram satisfatoriamente as escolas rurais das condiçóes necessárias ao seu funcionamento e, portanto, não conseguiram atingir o seu cotidiano para transformá-las em favor de seus sujeitos; silêncio também sobre o estatuto sócio- profissional de seus professores, que não tinham formação além do estudo primário, e, ainda, silêncio da academia, que só timidamente toma esse fenômeno como objeto de pesquisa. Com relação a esse último, de acordo com Brandão (1986, p. 12-13, grifos do autor):

O professor leigo é considerado um liminar estabelecido. Reconhecido oficialmente como um professor e incluído na folha de pagamento de inúmeras Secretarias de Educação de estados do país, ele não faz, no entanto, parte de seu quadro legítimo e não se inclui, portanto, em uma suposta carreira de magistério. Há uma quantidade muito pequena de estudos a seu respeito (espero que a bibliografia do presente Em Aberto me desminta) e sequer a sua condição e as suas características profissionais são adequadamente conhecidas entre nós.

A partir da reflexão sobre esses silêncios que envolvem o rural, as escolas aí instaladas e os seus professores, a discussão que propusemos para Educação no meio rural, políticas, espaço e temporalidades - tema da presente mesa - incidirá

5 Uma vez que náo construímos uma escola específica para atender às particularidades do mundo rural, concordamos com Afonso (2016, p. 44) que a melhor forma de nomear tais instituiçôes é como "[...] escolas em meio rural [...]". Entretanto, não podemos ignorar que ao denominá-la escola rural está se marcando uma diferença real em relação às instituiçóes que funcionavam no meio urbano, conforme discutiremos neste texto. 
sobre alguns dos problemas que perpassavam o espaço rural e as suas escolas, bem como sobre as táticas empreendidas por seus professores para se apropriarem do espaço e transformarem-no em lugar pleno de significações. Para tanto, o texto partirá de alguns obstáculos do tempo presente que afetam o rural como espaço e, de outro lado, como lugar de escolarização; na sequência, analisará como essas adversidades se apresentaram no passado para, enfim, discutir o papel representado pelos professores leigos das escolas rurais na constituição da escola como um lugar.

Trabalho e escola rural hoje e ontem: resultado das políticas

Para a compreensão dos problemas que afetam o meio rural e a complexa história de suas escolas começaremos, pois, pelo tempo, esse senhor de todos os destinos, mas o tempo presente, afinal, como ensinava Duby (1999, p. 9), "O historiador [...] tem o dever de não se fechar no passado e de refletir assiduamente sobre os problemas de seu tempo"

No Brasil, tramita no Congresso Nacional o Projeto de Lei (PL) no 6.442/2016, que "Institui normas reguladoras do trabalho rural e dá outras providências", de autoria do deputado Nilson Leitáo, do Partido da Social Democracia Brasileira (PSDB) do estado do Mato Grosso. Dentre as propostas de mudanças contidas nesse Projeto com vistas a alterar a regulamentação do trabalho rural, duas são de particular interesse para o tema que nos afeta nessa discussão, a saber, aquela que envolve a remuneraçáo e a outra que diz respeito à jornada de trabalho. Relativamente à primeira questáo, o PL prevê que o trabalhador rural poderá receber remuneração de qualquer espécie, o que implicará a possibilidade de o salário ser substituído pelo pagamento das despesas com comida e habitação; ainda nesse aspecto, a remuneração também poderá ser feita com parte da produção e concessão de terras. No tocante ao segundo ponto do PL, se aprovado da forma como está, a jornada de trabalho poderá ser estendida para até 12 horas, além de se poder instituir o fim do descanso semanal, uma vez que passará a ser permitido o trabalho contínuo por até 18 dias. Ficará permitida, ainda, a venda integral das férias pelos trabalhadores que residirem no local de trabalho e será liberado o trabalho aos domingos e feriados sem a apresentação de laudos de necessidade. Conforme Nunes (2017, não paginado, grifos do autor):

Hoje, a jornada rural segue a mesma regra da urbana, limitada a 44 horas semanais. No campo, para essa conta fechar, são turnos de oito horas de segunda a sexta e de quatro horas aos sábados. Mas quando se fala em trabalho rural - uma atividade braçal e muitas vezes ao ar livre - oito horas já são extenuantes. Por isso, como explica Antônio Lucas, são comuns acordos de jornadas de 36 horas 
semanais, especialmente no plantio e na colheita. 'Daí ir para 12 horas é um completo absurdo'.

E nós que pensávamos que a exploração do trabalhador, própria do início da Revolução Industrial no século XVIII, havia sido extirpada, que já fosse uma página virada do passado...

No que concerne à escola que funciona nesse mesmo espaço onde as relaçóes de trabalho estão em vias de sofrerem um retrocesso inimaginável, no início da década de 2000, os dados que emergiram dos estudos realizados no âmbito do Programa de Estudos sobre a Educaçáo no Meio Rural do Brasil (uma parceria entre o Instituto Nacional de Estudos e Pesquisas Educacionais Anísio TeixeiraINEP, Secretaria de Educação Infantil e Fundamental-SEIF e Banco Mundial) também evidenciaram inúmeros problemas, quais sejam, tempo reduzido de escolaridade obrigatória dos alunos, escolas desfavorecidas no que concerne à infraestrutura, equipamentos e materiais didáticos, dentre outros (BOF, 2006). Após apresentar e discutir os dados estatísticos relativos à realidade da escolarização no meio rural, um dos artigos desse estudo, em cujo título, Perfil estatístico da educação rural: origem socioeconômica desfavorecida, insumos escolares deficientes e resultados inaceitáveis, já se evidencia o resultado obtido na pesquisa, apresenta a seguinte conclusão:

1. As crianças da área rural têm origem socioeconômica familiar que as coloca em desvantagem com as crianças de origem urbana.

2. As escolas, nas quais estudam as crianças da área rural, estão muito pior equipadas e contam com professores menos treinados que as escolas nas quais estudam as crianças urbanas.

3. Os resultados nas escolas rurais em termos de defasagem idade-série e taxas de aprovaçáo são muito piores para as crianças rurais que para as crianças urbanas. (SOARES; RAZO; FARIÑAS, 2006, p. 67).

No estado de Minas Gerais, por exemplo, quatro anos após a publicação desse estudo pelo INEP, Silva apontava a seguinte realidade no meio rural:

[...] a existência de bibliotecas nas escolas que oferecem o ensino fundamental no Estado indica que, enquanto nos estabelecimentos do meio urbano elas existem em $82,51 \%$ das escolas, no meio rural estáo em apenas $10,61 \%$ desses estabelecimentos. [...] 22,97\% nâo 
possuíam energia elétrica, apenas 4,54\% dispunham de computador e menos de 1\% delas ofereciam laboratórios de ciências e de Informática e tinham acesso à Internet. (SILVA, 2010, p. 59).

Resta questionar o que apresentam em comum o PL no 6.442/2016 e os dados contidos no estudo do INEP, além da visível precarização das condiçóes de trabalho e das dificuldades verificadas nas escolas acima mencionadas? Seria o espaço onde se desenrolam as tramas, o saber, o rural? Acreditamos que não, pois crer que a desvalorizaçáo do trabalhador do meio rural e os problemas existentes na escolarização nesse mesmo meio sejam decorrência apenas e inevitável do espaço onde se encontram tal trabalho e tal escola seria o mesmo que partilhar do determinismo geográfico e do positivismo na história e desconsiderar o papel ativo dos sujeitos na construção e nos usos do espaço e, por conseguinte, na sua transformação e produção da realidade. Acreditamos que tanto o determinismo geográfico quanto o positivismo já tenham sido suficientemente criticados e não iremos nos deter aqui nessa questão, ao contrário, procuraremos discutir alguns dos fatores que contribuíram para a produção desse rural, onde tem se perpetuado a falta de infraestrutura (transporte, habitação e saneamento), precarização das condiçóes de trabalho (baixos salários e desregulamentação dos direitos dos trabalhadores) e escolas débeis (professor desvalorizado, espaços improvisados, inexistência de transporte, carência de material didático, dentre outros).

Tais fatos não são novos, ao contrário, uma imersão na história permite apreendê-los lá atrás. Então vejamos... No tocante ao trabalho rural, somente na segunda metade do século XX foi aprovada uma legislação social que estendeu aos trabalhadores do campo alguns direitos já garantidos aos trabalhadores urbanos; tratava-se do Estatuto do Trabalhador Rural, aprovado em 1963.

Definindo o trabalhador rural como 'toda pessoa física que presta serviços a empregador rural... mediante salário pago em dinheiro ou in natura, ou parte em dinheiro e parte in natura', a Lei no 4.214 tornou obrigatória a concessão de carteira profissional a todo trabalhador rural maior de 14 anos independente do sexo, estipulou a jornada de trabalho em oito horas e instituiu o direito ao aviso prévio e à estabilidade. Nenhum trabalhador poderia ser remunerado com base inferior ao salário mínimo regional. Os trabalhadores menores de 16 anos receberiam a metade do salário atribuído ao adulto. Além disso, o estatuto assegurou o direito ao repouso semanal e às férias remuneradas. (LAMARÃO; MEDEIROS, [199-?], não paginado, grifo dos autores). 
Tal regulamentação não serviu, naquele momento, para atenuar os problemas subjacentes ao trabalho no meio rural, pois o instrumento jurídico, ao criar o Fundo de Assistência e Previdência do Trabalhador Rural (Funrural), ao assegurar direitos à jornada de oito horas de trabalho e determinar o pagamento do salário mínimo, ocasionou um forte desemprego, uma vez que os proprietários rurais se negavam a assumir os custos provenientes da legislação. Não obstante, a partir da Constituição de 1988 novas regulamentaçóes para o trabalhador rural foram aprovadas e algumas implementadas ${ }^{6}$; hoje, contudo, conforme comentamos no início do texto, tais garantias encontram-se em processo de extinção.

Relativamente à história das escolas brasileiras instaladas em meio rural, o seu funcionamento também tem sido historicamente caracterizado pelas dificuldades de toda ordem: insuficientes recursos para o investimento, seja em infraestrutura (prédios, saneamento, transporte, bibliotecas, laboratórios, etc.), seja na valorização dos professores (salários, formação, capacitação, condiçóes de trabalho); inexistência de incentivo aos alunos para a permanência na escola e prosseguimento nos estudos (LIMA; MUSIAL, 2016). Em Minas Gerais, por exemplo, a situação dos professores das escolas rurais no final da década de 1940 não se constituía em motivo para comemoração, ao contrário, conforme estudo realizado por Lourenço Filho (2001, p. 88):

Em 1947, assumiu o posto de Secretário de Educaçáo de Minas Gerais o sr. Abgar Renault, que dantes havia desempenhado as funçóes de diretor do Departamento Nacional de Educação. Ao examinar a situação do ensino primário, no Estado, verificou que as escolas rurais, em número superior a $7 \mathrm{mil}$, estavam na maioria entregues à administração dos municípios; que os mestres, nessas escolas, em $91 \%$ delas, eram regentes leigos ou desprovidos de qualquer preparação anterior em escolas normais; e, ademais, que tais mestres, inteiramente desprovidos de orientação com que pudessem melhorar seu trabalho, recebiam salários ínfimos.

6 "A Constituição de 1988 unificou os direitos de trabalhadores urbanos e rurais, quer no que se refere às questões trabalhistas, quer no que se refere aos temas previdenciários. No entanto, ela ainda manteve a garantia, para os rurais, de reclamação dos direitos não respeitados por dois anos após o rompimento do contrato de trabalho. No que se refere ao FGTS, também foi estendido aos trabalhadores do campo, eliminando o direito à estabilidade de emprego para os permanentes." (LAMARÃO; MEDEIROS, [199-?], não paginado). 
Enfim, uma lista de obstáculos que parece infindável e intercontinental, uma vez que pesquisas acerca da história da escolarização rural produzidas na América Latina e na Europa apontam para realidades muito semelhantes (AFONSO, 2016; LIMA; MUSIAL, 2016; PÉREZ; PÉREZ, 2009; WERLE, 2007).

Resta-nos indagar: o que justificaria o desprestígio do meio rural, visível nas precárias condiçóes de trabalho e nas fragilidades das condições de escolarização de suas populaçôes? Como explicar, além disso, que esse seja um problema comum no Ocidente? Como assinalou Rama (2015, p. 25), a propósito da construção das cidades na América Latina, com a chegada dos colonizadores no Século XVI iniciou-se um processo de urbanização cujo objetivo era materializar no espaço físico uma dada noção de ordem social e, com isso, "[...] o futuro que ainda não existe, que é apenas sonho da razão, é a perspectiva genética do projeto." Mas essa utopia não teria também presidido a história do Ocidente Moderno? Afinal, o espaço destinado ao rural no projeto de modernidade também não era novo,

Pois desde Marx tornou-se um chavão, em determinados contextos, falar do caráter progressista do capitalismo e, dentro dele, da urbanização e da modernização social. As grandes acusaçóes dirigidas ao capitalismo e ao extenso catálogo de misérias por ele criadas nas fábricas e nas cidades sempre coexistiram, dentro de uma certa visão histórica, com essa utilização repetitiva do termo 'progressista' para designar esses mesmos eventos. (WILLIAMS, 2011, p. 67-68, grifo do autor).

Portanto, não se pode desconsiderar que o silêncio sobre o rural no aniversário de 129 anos do município de Uberlândia, a proposição de uma legislação trabalhista que desregulamenta os parcos direitos conquistados pelos trabalhadores do campo e a situação frágil das escolas em meio rural sejam expressôes de um mesmo movimento, a saber: uma organização da produção e circulação de riquezas no âmbito do capitalismo e, como decorrência, uma dada opçáo política das elites que propuseram e protagonizaram os projetos econômicos e sociais para a sociedade. Dentre tais projetos, situa-se, por exemplo, aquele da Aciapu, em Uberlândia, nos anos 1930, cuja polêmica acerca da palavra agricultura na denominação da Associação já diz muito sobre silêncios, esquecimentos e preconceitos que incidem sobre o rural. Em razão disso, podemos aquilatar que o desprestígio do mundo rural e de suas escolas seja decorrência de sucessivos projetos políticos e não meramente caso do acaso; afinal, os usos que fazemos do espaço orientam-se também por 
interesses políticos e estratégias de controle sobre os sujeitos que o ocupam. Conforme analisou Viñao Frago (1995, p. 69, tradução nossa),

O espaço físico é, para o ser humano, espaço apropriado - território - e espaço organizado e habitado - lugar. Neste sentido, o espaço é uma construçáo social e o espaço escolar uma das modalidades de sua conversão em território e lugar. Daí que o espaço não é jamais neutro, senáo signo, símbolo e marca da condição e relaçóes daqueles que os habitam. O espaço fala e comunica; portanto, educa. Mostra, a quem sabe ler, o emprego que o ser humano faz do mesmo. ${ }^{7}$

Com efeito, pensar sobre o espaço implica considerar os seus usos e admitir que sejam construídos pelos seus sujeitos, sendo a ação dos ocupantes [do espaço] e os conflitos a ela inerentes a condição para tirá-lo da impessoalidade e dotá-lo das marcas da afetividade, sensibilidade e disputas que o tornarão familiar, personalizado, ou seja, o configurarão como um lugar, uma vez que " $O$ que começa como espaço indiferenciado transforma-se em lugar à medida que o conhecemos melhor e o dotamos de valor" (TUAN, 2013, p. 14).

Nesse sentido, interessa-nos mais compreender como a escola rural converte o espaço indiferenciado do meio rural num lugar de circulaçáo de saberes, culturas, práticas e sociabilidades. Com isso acreditamos contribuir para romper o silêncio que persiste tanto no que concerne ao fato social, o rural e as suas escolas, quanto no que diz respeito ao objeto de estudo, a pesquisa sobre esse mesmo fenômeno. Para tal compreensão acreditamos ser fundamental encontrar os seus sujeitos, em particular, para o que nos importa neste momento, os seus professores. Esse encontro, é claro, deve ser precedido de uma busca, busca essa que nos remete às pesquisas que temos desenvolvido no âmbito do Grupo de Pesquisas em História do Ensino Rural (GPHER), na Universidade Federal de Uberlândia (UFU), sobre as quais discorremos nesta última parte do texto.

7 Conforme o original: "El espacio físico es, para el ser humano, espacio apropiado - território - y espacio dispuesto y habitado - lugar. En este sentido, el espacio es una construccción social y el espacio escolar una de las modalidades de su conversión en território y lugar. De ahí que el espacio no sea jamás neutro sino signo, símbolo y huella de la condición y relaciones de quienes los habitan. El espacio disse e comunica; por tanto, educa. Muestra, a quien sabe leer, el empleo que el ser humano hace del mismo." (VIÑ̃̃O FRAGO, 1995, p. 69). 


\section{As artes de ensinar: professores leigos da escola rural}

Dentre as investigaçóes desenvolvidas pelo GPHER, ressalto aquelas que envolvem as histórias e memórias de seus sujeitos: professores que atuaram nas escolas rurais no município de Uberlândia no período de 1930 a 1979, por meio das quais temos procurado compreender quem foram esses professores, qual a sua formação, idade, sexo, origem social, condições de trabalho, quais foram as suas práticas de ensino e quais representaçôes construíram sobre o seu ofício, o meio rural, as escolas, os alunos, a comunidade no entorno da escola, etc. (SILVEIRA, 2008; RIBEIRO, 2009; BARROS, 2013; ASSIS, 2017; FERREIRA, 2017; TANNÚS, 2017). ${ }^{8}$

No período compreendido pelas pesquisas desenvolvidas pelos integrantes do GPHER, 1930-1970, as escolas primárias localizadas no meio rural ficavam sob a competência administrativa do município e se caracterizavam pela organização na modalidade de escolas isoladas, multisseriadas e unidocentes. Esses três qualificativos se, de um lado, atestavam os parcos recursos destinados a essas instituiçôes pelo poder público municipal, assim os tímidos investimentos dos Estados e do Governo Federal, de outro denotavam as dificuldades com as quais os seus professores se deparavam: isolamento pedagógico e sobrecarga de trabalho e de atribuiçóes. Sendo isoladas, tais escolas não contavam no seu quadro de pessoal com nenhum outro profissional a não ser o próprio professor, que acumulava as atribuiçôes inerentes ao ensino com outras de gestão, orientação educacional e serviços gerais, uma vez que deveria cuidar da administração burocrática intrínseca à educaçáo escolar, do planejamento das aulas, além da limpeza da sala de aula e preparação do lanche. ${ }^{9}$ Todas essas atividades eram desempenhadas à revelia de uma formaçáo técnica em Curso Normal, uma vez que no período em tela a maioria desses professores havia concluído apenas o ensino primário; eram, portanto, professores leigos, conforme já referido nas páginas precedentes.

O contexto no qual se verificou a insuficiente escolaridade desses professores pode ser explicado a partir do estudo publicado por Lourenço Filho (2001), segundo o qual, em 1947, registrou-se a iniciativa do governo federal em criar o ensino normal regional, ou rural, com o objetivo de qualificar os professores

8 Mencionamos apenas as dissertaçôes, teses e relatórios de pós-doutorado; ao seu lado há também pesquisas de iniciação científica e monografias que não se encontram referenciadas.

9 Excluindo-se daí os relatos obtidos de alguns professores segundo os quais lhes eram dirigidas solicitaçóes diversas para resolverem problemas da comunidade rural que não se relacionavam diretamente com a escola (LIMA; ASSIS, 2013). 
para o trabalho em escolas localizadas no meio rural. $\mathrm{Na}$ mesma ocasião foram propostos cursos de treinamento e aperfeiçoamento para os profissionais em serviço. A iniciativa de pôr essas escolas em funcionamento relacionava-se com as estratégias adotadas por aquele governo com o intuito de minorar o alto índice de analfabetismo vigente no país, sobretudo nas áreas rurais.

Conforme já comentamos, de acordo com Lourenço Filho (2001), era lastimável a condição de trabalho dos professores das escolas rurais em Minas Gerais, uma vez que $91 \%$ deles eram regentes leigos. A constataçáo de tal realidade engendrou a criação nesse Estado de nove Cursos Normais Regionais para a formação de professores para atuação no meio rural. No entanto, o município de Uberlândia não recebeu nenhuma dessas instituiçóes, o que concorreu para que os seus professores apresentassem insuficiente escolaridade ainda no final dos anos de 1960, muitos apenas com o certificado de conclusão do ensino primário. Daí que a profissão lhes chegava antes da formação especializada para exercêla, o que lhes exigia um trabalho adicional, para cuja realização mobilizavam os parcos conhecimentos escolarizados, os quais haviam se apropriado nos breves anos de escolaridade, e os saberes oriundos da cultura empírica adquiridos no contato familiar, social e no próprio ambiente de trabalho, a escola primária rural. Os seguintes excertos de algumas entrevistas realizadas pelos pesquisadores do GPHER com ex-professoras de escolas rurais constituem exemplos deste trabalho:

[Ensinava] Só Português, Matemática, História e Geografia. Depois começou é Conhecimentos Gerais né, aí era bom. A gente pegava até nas revistas coisas assim, novidades para passar para os meninos, do jornal a gente ouvia e passava também para os meninos para eles ficarem mais por dentro dos acontecimentos e assim ia levando né, ia passando [...] $\left(\right.$ MLC, 2011) ${ }^{10}$.

Quando eu comecei a dar aula já eram duas professoras, para trás era uma professora com quatro, com três séries, quatro porque falava primeira $A$ e primeiro $B$, segundo e terceiro, não tinha quarta. Mas era primeiro $\mathrm{A}$, primeiro $\mathrm{B}$, segunda série e terceira série. Era tudo junto. Separava por fileiras de carteiras, de cadeirinhas. (JFRM, 2011).

10 A realização das entrevistas citadas neste artigo foi aprovada pelo Comitê de Ética em Pesquisas (CEP), da Universidade Federal de Uberlândia (Protocolo $n^{\circ} 013 / 10$ ), o qual exigiu a preservação da identidade dos entrevistados e por essa razão os seus nomes foram abreviados, tendo sido informadas apenas as suas iniciais. 
Antes [...] era esforço da gente. A gente que tinha que pesquisar, comprar livros, estudar, além de náo ter a capacidade, a gente náo tinha o material, a gente que tinha que pesquisar. (ARS, 2011).

Conquanto a relevância que essa cultura empírica apresenta para se compreender a história da educaçáo rural, sobretudo quando se tratam de professores sem formação técnica, comumente não é valorizada no âmbito de uma dada tradição escolarizada. Conforme Escolano (2011, p. 117, tradução nossa):

Chama a atençáo que a este acervo experiencial tenha sido negado o estatuto não apenas de ciência, mas também o de saber, exclusão que se se acentua sobretudo a partir daquilo que o positivismo, desde fins do XIX, legitimara como sendo as novas regras de verdade da pretensa ciência da educação, e de supor que esta, a educação, somente deveria ser gerida mediante as pautas procedentes da racionalidade científica na qual a positividade do novo discurso se assentava. ${ }^{11}$

Em se tratando do meio rural, essa desqualificação tornava-se ainda agudizada uma vez que era robustecida pelo histórico de representações depreciativas de seus habitantes, de seus modos de vida, de suas experiências formativas e de suas práticas culturais, cuja tipificação não se restringe à modernidade e tampouco é exclusiva do Brasil. No que diz respeito ao primeiro aspecto, Sennet (2014, p. 35, grifos do autor) chama atenção para o fato de que fazia parte do próprio idioma dos gregos na era de Péricles preconceitos relativos ao homem do campo, uma vez que "[...] asteios [urbano] e agroikos [rural], também podem ser traduzidas como 'refinado' e 'embrutecido' ". De outro lado, Afonso (2016) discute de forma detalhada como também em Portugal na Primeira República os sujeitos do meio rural eram caracterizados a partir de traços inferiorizados e depreciativos.

Não obstante, para o que nos interessa mais de perto, temos que problematizar essas representaçóes, apreendê-las em um campo de concorrências e competiçóes (CHARTIER, 1988), e, na senda do que ressalta Escolano (2011), abordar a

11 Conforme o original: "Llama a atención que a este acervo experiencial lehaya sido negado el estatuto no ya de ciencia sino incluso de saber, exclusión que se acentúa sobre todo a partir de que el positivismo, desde fines del XIX, legitimara lasnuevasreglas de verdad de la pretendida ciencia de laeducación, y de dar por supuesto que ésta, laeducación, sólodebería ser gestionada mediante las pautas procedentes de laracionalidad científica enla que lapositividaddelnuevo discurso se sustentaba" (ESCOLANO, 2011, p. 117). 
história da escola em meio rural a partir das práticas construídas e mobilizadas em seu interior. "Esta tarefa será aquela que permitirá entender e interpretar os modos da cultura escolar existentes, a tradição societária disponível e outras variáveis explicativas de como a escola produziu suas próprias respostas [...] (ESCOLANO, 2011, p. 118, tradução nossa) ${ }^{12}$.

Dessa maneira, sem desqualificar o papel que a formação normal desempenha na atuação do professor e tampouco fazer apologia às políticas de formação que não atingiam o professor das áreas rurais, faz-se necessário aquilatar a função que a formação pela cultura empírica representou para os professores das escolas rurais, uma vez que a sua presença era central naquele cotidiano escolar. A valorização dos saberes construídos na vida cotidiana é fundamental para se dimensionar a importância do trabalho exercido por esses sujeitos nas comunidades rurais onde alfabetizaram as crianças, assim como os significados atribuídos à sua permanência naquele meio.

Ao se considerar a cultura empírica como uma das dimensôes da formação dos professores que atuaram nas escolas em meio rural torna-se possível compreender o cotidiano escolar na perspectiva do que propóe Certeau (2009, p. 91), como o locus da inventividade, da apropriação criativa e sempre transformadora dos seus consumidores, aqueles denominados pelo historiador francês de "[..] poetas de seus negócios [...]", "[...] inventores de trilhas na selva da racionalidade funcionalista”. Nessa abordagem situa-se, por conseguinte, a possibilidade de recolocar tais professores na condição de sujeitos e não apenas de vítimas do poder público que secundarizou a organizaçáo das escolas situadas em meio rural e, por consequência, não forneceu os meios necessários para que cumprissem o papel que lhes era reservado, dado que tais instituiçóes dependiam da iniciativa e da colaboração direta dos particulares para funcionarem.

Assim, a história das escolas rurais se confunde com a ação política de seus professores que, a despeito de todas as adversidades, criavam táticas para ensinar aos alunos as operaçóes aritméticas, para iniciá-los na leitura e escrita, sobretudo. Por isso, acreditamos que, segundo advertiu Marc Bloch (2001) a propósito da historiografia, a história, tal qual o monstro da lenda, precisa buscar a carne humana, e, no caso da história da educação que objetive compreender e problematizar a escola rural, suas temporalidades e políticas, deve fazer emergir os seus sujeitos em questão, os professores. Do ponto de vista da pesquisa, essa é

12 Conforme o original: "Esta tarea es la que permitirá entender e interpretar los modos de la cultura escolar e fectual, la tradición societária disponible y otras variables explicativas de como la escuela ha generado sus propias respuestas [...]" (ESCOLANO, 2011, p. 118). 
uma estratégia fundamental para se romper o silêncio das políticas e dos políticos com o qual se pretende tornar invisíveis o meio rural e as suas escolas, assim como ignorar os seus sujeitos, aqueles que são identificados por Certeau (2009, p. 55) como homem ordinário, herói comum que "[...] nas representaçóes escritas, vai progredindo. Pouco a pouco ocupa o centro de nossas cenas científicas."

\section{Considerações Finais}

Diante do exposto, concluímos que à pesquisa sobre a história da escolarização no meio rural, sobretudo até o final dos anos 1960, subjazem dois desafios teórico-metodológicos, quais sejam: a compreensão que se aproprie do espaço rural, levando-se em conta a perspectiva histórica e uma apreensão ampliada da noção de formação de professores, o que implicará um alargamento das fontes de pesquisa empregadas.

No que diz respeito ao primeiro aspecto, conforme discutimos, é fundamental uma análise por meio da qual se desmistifiquem as abordagens naturalizadas sobre os problemas que comprometeram - sendo que alguns ainda persistem - o funcionamento da escola em meio rural. É preciso rechaçar discursos e pseudoteorias segundo os quais esses problemas seriam resultado inevitável de as escolas rurais se encontrarem num espaço onde a escassez de recursos e a rusticidade de seus habitantes supostamente existiriam como uma condiçáo natural. Cabe, portanto, desnaturalizar esse fenômeno e admitir que tanto no rural em dimensão ampliada quanto mais especificamente em suas escolas encontram-se os resultados de projetos políticos oriundos de um modelo de produção, apropriação e acumulação de riquezas que vem há séculos explorando a sua população e solapando os recursos materiais, naturais e humanos. Portanto, conforme ressaltou Gonçalves (2003, p. 46) a propósito das memórias e representaçóes sociais construídas pelos trabalhadores do meio rural nos Vales do Aço e Rio Doce em Minas Gerais, "[...] não se deve distinguir as formas de trabalho e de inserção do agricultor no sistema de produção capitalista como uma evolução natural ou necessária." Assim como não é natural a condição desfavorecida das escolas em meio rural inseridas nesse mesmo sistema.

A necessidade de se ir além das fontes normativas e prescritivas que regulamentaram o ensino primário rural, assim como a urgência em se admitir na análise categorias e conceitos que permitam apreender as práticas e o cotidiano dessas escolas, e com isso redimensionar a compreensáo acerca da formação docente, constitui-se no segundo desafio para as nossas pesquisas, cujo enfrentamento implica, primeiramente, buscar outros documentos, tais como: 
cadernos escolares onde tenham sido registradas as atividades desenvolvidas nas aulas e o planejamento dos professores; história oral; narrativas autobiográficas (histórias de vida, diários pessoais e correspondência, por exemplo); fotografias; literatura e outros. Acreditamos, portanto, ser necessário recorrer às escritas ordinárias ${ }^{13}$, escritas epistolares, narrativas autobiográficas e iconografia em busca de indícios que permitam compor os aspectos do cotidiano das escolas rurais, conhecer os seus sujeitos e apreender as suas práticas.

Em síntese, as limitações de orçamento e a consequente debilidade das escolas, somadas à insuficiente formação de seus mestres, tornaram o ensino rural tributário da inventividade de seus professores, daqueles que, de acordo com uma das professoras entrevistadas, aprendiam e ensinavam ao mesmo tempo (MARC, 2011). Será, portanto, na dimensão das táticas e dos usos dos consumidores criativos novamente Certeau (2009), cujas marcas encontram-se na cultura empírica, que poderão ser formuladas muitas questóes acerca da história da escola em meio rural. Essas questōes ampliarão a compreensão científica do fenômeno e, por fim, auxiliarão os seus sujeitos a buscarem um futuro mais auspicioso para a educação, pois "[..] colocar o homem ou, melhor dito, o ser humano, para ser politicamente correto, no centro das preocupaçôes significa recuperar sua condição de fazedor de história, de agente de seu próprio destino" (CARVALHO, 2005, p. 453).

\title{
Referências
}

\author{
AFONSO, José António. Escolas Rurais na 1a República Portuguesa (1910 \\ - 1926): discursos e representaçóes sobre a periferia. Santo Tirso, Portugal: \\ WHITEBOOKS, 2016. 122 p.
}

ASSIS, D. A. Inventoras de Trilhas: histórias e memórias das professoras das escolas rurais do município de Uberlândia (1950 - 1980). 2017. Relatório (Qualificação de mestrado) - Faculdade de Educação, UFU, Uberlândia, 2017.

13 As escritas ordinárias são referidas aqui conforme as definem Fabre (1993), Mignote Cunha (2006) em seus estudos a respeito da cultura escolar. Segundo tais autores, sob tal tipificaçáo, encontram-se vestígios que podem ser interrogados para a compreensão da história da escolarização, tais como: bilhetes, cadernos, correspondência, boletins, relatórios internos às escolas, dentre outros. Produzidas por pessoas comuns e sem, necessariamente, gozarem do estatuto científico e nem literário, tais escritas permaneceram marginalizadas por uma historiografia da educação de tradição conservadora e positivista; não obstante os seus conteúdos apresentam considerável potencial para a compreensão das culturas escolares e no âmbito dessas possibilitam apreender aspectos do cotidiano das escolas, em particular daquelas situadas em regiōes periféricas e rurais, sobre as quais pouca documentação encontra-se preservada. 
ASSOCIAÇÃO COMERCIAL, INDUSTRIAL E AGROPECUÁRIA DE UBERLÂNDIA. Ata da Assembléia de organizaçáo da Associaçáo Comercial, Industrial e Agropecuária de Uberlândia, realizada no dia 15 de out. 1933. Uberlândia, 1933. Livro n. 01, p. 01- verso e 02.

BARROS, Josemir A. Organizaçáo do Ensino Rural em Minas Gerais, suas muitas faces em fins do XIX e início do XX (1899-1911). Tese (Doutorado em Educação)- Faculdade de Educação, UFU, Uberlândia, 2013.

BLOCH, Marc. Apologia da história: ou o ofício do historiador. Rio de Janeiro: Zahar, 2001.

BOF, A. M. (Org.). A educaçáo no Brasil rural. Brasília, DF: Instituto Nacional de Estudos e Pesquisas Educacionais Anísio Teixeira, 2006. 236 p. Disponível em: <http://www.publicacoes.inep.gov.br/arquivos/\%7B9D3260AB-473147E4-B8F8-20F669F3172F\%7D_miolo_1_educacao_brasil_rural.pdf>. Acesso em: 10 ago. 2017.

BRANDÃO, C. Os professores leigos. Em Aberto, Brasília, DF, ano 5, n. 32, p. 12-15, out./dez. 1986.

CARVALHO, J. M. de. O historiador às vésperas do terceiro milênio. In: CARVALHO, J. M. Pontos e bordados: escritos de história e política. 2. reimp. Belo Horizonte: UFMG, 2005. p. 441-457.

CERTEAU. Michel de. A invenção do cotidiano: artes do fazer. Tradução de Ephraim Ferreira Alves. 16. ed. Petrópolis: Vozes, 2009. v. 1.

CHARTIER, Roger. A história cultural: entre práticas e representaçóes. Lisboa: DIFEL, 1988.

DUBY, G. Ano 1000, Ano 2000: na pista de nossos medos. São Paulo: UNESP; Imprensa Oficial do Estado, 1999.

ESCOLANO, A. Arte y oficio de enseñar. In: COLOQUIO INTERNACIONAL DE HISTORIA DE LA EDUCACIÓN. Arte y oficio de enseñar. Dos siglos de perspectiva histórica, 16., 2011, El Burgo de Osmã. Valladolid-Es. Anais... Valladolid-Es: Gráficas Varona, 2011, p. 17-26.

FABRE, Daniel (Org.). Écritures Ordinaires. Paris, França: Centre Georges Pompidou. Bibliothéque Publique d' Informatión, 1993. p. 11-94.

FERREIRA, N. V. C. A história escola normal rural brasileira nos anos de 1942 - 1963. 2016. Projeto de pesquisa (Estágio de pós-doutorado) - Faculdade de Educação, Programa de Pós-Graduação em Educação, UFU, Uberlândia, 2016. 
GONÇALVES, M. T. Espaço rural em transformação: um lugar de (qual) memória? História \& Perspectivas, Uberlândia, (29 e 30), p. 33-70, jul./dez. 2003/jan./jun. 2004.

LAMARÁO, Sérgio; MEDEIROS, Leonilde S. de. Estatuto do Trabalhador Rural. In: Verbete. FGV/CPDOC, [199-?]. Disponível em: <http://www.fgv. $\mathrm{br} / \mathrm{cpdoc} /$ acervo/dicionarios/verbete-tematico/estatuto-do-trabalhador-rural>. Acesso em: 04 ago. 2017.

LIMA, S. C. F.; ASSIS, D. A. Poetas de seus negócios - Professoras leigas das escolas rurais (Uberlândia-MG, 1950 a 1979). Cadernos de História da Educaçáo, UFU, Uberlândia, v. 12, p. 313-332, 2013.

LIMA, Sandra C. F. de; MUSIAL, G. B. da S. (Org.). Histórias e memórias da escolarizaçáo das populaçóes rurais: sujeitos, instituições, práticas, fontes e conflitos. Jundiaí: Paco, 2016.

LOURENÇO FILHO, Manoel, B. A formaçáo de professores: da Escola Normal à Escola de Educação. Brasília, DF: INEP, 2001. 125 p. (Coleção Lourenço Filho, 4. Organizador: Ruy Lourenço Filho).

MIGNOT, Ana Chrystina Venâncio; CUNHA, Maria Teresa Santos. Razóes para guardar: a escrita ordinária em arquivos de professores/as. Revista Educaçáo em Questáo, Natal, UFRN, v. 25, n. 11, p. 40-61, jan./abr. 2006.

NORA, Pierre. Entre a memória e História: a problemática dos lugares. Tradução de Yara AunKhoury. Projeto História: Revista de Programa de Estudos PósGraduados em História e do Departamento de História da PUC-SP, São Paulo, p. 7-28, dez. 1993.

NUNES, Dimalice. PL do trabalho rural "revoga a Lei Áurea”, diz procurador. Carta Capital. 5 maio 2017. Disponível em: <https://www.cartacapital.com.br/ sociedade/pl-do-trabalho-rural-201 crevoga-a-lei-aurea201d-diz-procurador $>$. Acesso em: 14 jul. 2017.

PÉREZ, Teresa González; PÉREZ, Oresta López. (Org.). Educación rural em Iberoamerica. Experiencia histórica y construcción de sentido. Madrid: Anroart Ediciones, 2009.

POLLAK. M. Memória, esquecimento, silêncio. Estudos Históricos, Rio de Janeiro, v. 2, n. 3, p. 3-15, 1989. Disponível em: <http://bibliotecadigital.fgv.br/ ojs/index.php/reh/article/view/2278/1417>. Acesso em: 4 ago. 2017.

RAMA, A. A cidade das letras. Sáo Paulo: Boitempo, 2015. 
RANCIÈRE, Jacques. Os nomes da história: um ensaio de poética do saber. São Paulo: EDUC; Pontes, 1994.

RIBEIRO, Cristiane Angélica. Escola rural e alfabetizaçáo em Uberlândia, 1936 a 1946. 2009, 145 f. Dissertação (Mestrado em Educação)- Faculdade de Educação, UFU, Uberlândia, 2009.

SENNET, Richard. Carne e Pedra. Rio de Janeiro: BestBolso, 2014.

SILVA, Helenice Rodrigues da. "Rememoração"/comemoração: as utilizações sociais da memória. Revista Brasileira de História, São Paulo, v. 22, n. 44, p. 425-38, 2002.

SILVA, Lourdes H. da. Cenários da Educaçáo no meio Rural de Minas Gerais. Curitiba: CRV, 2010.

SILVEIRA, Tânia C. da. História da Escola rural Santa Tereza (Uberlândia: 1934 a 1953). 2008, 145 f. Dissertação (Mestrado em Educação) - Faculdade de Educação, UFU, Uberlândia, 2008.

SILVEIRA, T.C.; RIBEIRO, C.A. O rural e o urbano nas atas de reuniōes da Associação Comercial, Industrial e Agropecuária de Uberlândia (ACIUB). In: LIMA, Sandra C. F. de; MUSIAL, G. B. da S. (Org.). Histórias e memórias da escolarizaçáo das populaçóes rurais: sujeitos, instituiçóes, práticas, fontes e conflitos. Jundiaí: Paco, 2016. p. 99-127.

SOARES, S.; RAZO, R.; FARIÑAS, M. Perfil estatístico da educação rural: origem socioeconômica desfavorecida, insumos escolares deficientes e resultados inaceitáveis. In: BOF, A. M. (Org.). A educaçáo no Brasil rural. Brasília, DF: Instituto Nacional de Estudos e Pesquisas Educacionais Anísio Teixeira, 2006. p. 47-68. Disponível em: <http://www.publicacoes.inep.gov.br/ arquivos/\%7B9D3260AB-4731-47E4-B8F8-20F669F3172F\%7D_miolo_1_ educacao_brasil_rural.pdf $>$. Acesso em: 9 ago. 2017.

TANNÚS, Márcia C. Memórias, história e representaçóes das escolas rurais do município de Uberlândia na Era Vargas (1930-1945). 128 f. Dissertação (Mestrado em Educação)- Faculdade de Educação, UFU, Uberlândia, 2017.

TUAN, YI-Fu. Espaço e lugar: a perspectiva da experiência. Traduçáo de Lívia de Oliveira. Londrina: Eduel, 2013.

VIÑAO FRAGO, A. Historia de la Educación y Historia Cultural - posibilidades, problemas, cuestiones. Revista Brasileira de Educaçáo, Campinas, n. 0, p. 6382, set./out./nov./dez. 1995. 
WERLE, Flávia O. C. (Org.) Educação rural em perspectiva internacional instituições, práticas e formação do professor. Ijuí: UNIJUÍ, 2007.

WILLIAMS, R. O campo e a cidade na história e na literatura. Tradução de Paulo Henrique Britto. São Paulo: Cia. das Letras, 2011.

\section{FONTES (ENTREVISTAS)}

ARS: depoimento [ago. 2011]. Entrevistadora: Danielle Angélica de Assis e Silvana de Jesus Gonçalves. Uberlândia, 2011 (52min35seg).

JFRM: depoimento [jul. 2011]. Entrevistadoras: Sandra Cristina Lima Fagundes e Silvana de Jesus Gonçalves. Uberlândia, 2011(1h 3min32seg)

MARC: depoimento [jul. 2011]. Entrevistadoras: Caroline A. Araujo, Danielle A. de Assis e Silvana de Jesus Gonçalves. Uberlândia, 2011(51min59seg).

MLC: depoimento [maio 2011]. Entrevistadoras: Caroline A. Araujo e Danielle A. de Assis. Uberlândia, 2011 (44min7seg). 